\title{
Increased hypoxemia in patients with COPD and pulmonary hypertension undergoing bronchoscopy with biopsy
}

This article was published in the following Dove Press journal:

International Journal of COPD

7 December 2015

Number of times this article has been viewed

\author{
Yoram Neuman ${ }^{1,3}$ \\ Matthew Koslow ${ }^{2,3}$ \\ Alona Matveychuk ${ }^{2,3}$ \\ Avigdor Bar-Sef' \\ Alexander Guber ${ }^{2,3}$ \\ David Shitrit ${ }^{2,3}$ \\ 'Division of Cardiology, ${ }^{2}$ Pulmonary \\ Department, Meir Medical Center, \\ Kfar Saba, Israel; ${ }^{3}$ Sackler Faculty of \\ Medicine, Tel Aviv University, Tel Aviv, \\ Israel
}

Correspondence: David Shitrit Pulmonary Department, Meir Medical Center, 59 Tchernichovsky Street,

Kfar Saba 4428I, Israel

$\mathrm{Tel}+97297472512$

Fax +9729740 4832

Email davids3@clalit.org.il
Background and objective: Patients with pulmonary hypertension $(\mathrm{PH})$ are considered to be at risk for complications associated with flexible bronchoscopy (FB), but data concerning the degree of $\mathrm{PH}$ are often lacking. We investigated whether COPD patients with $\mathrm{PH}$ who undergo bronchoscopy are at greater risk for complications.

Methods: This prospective study included 207 consecutive COPD patients undergoing FB. All underwent an echo-Doppler to evaluate pulmonary artery pressure on the day of the bronchoscopy procedure. Pulmonologists were blinded to the echocardiogram results.

Results: A total of 167 patients $(80.7 \%)$ had normal pulmonary pressure. The remaining 40 patients (19.3\%) had PH: 27 (13.0\%) mild, eight (3.9\%) moderate, and five (2.4\%) severe. Noninvasive hemodynamic parameters between groups before and after FB were similar. Two patients with normal pulmonary pressure developed supraventricular tachycardia. None developed hemodynamically significant dysrhythmia. Bleeding episodes between groups in bronchoalveolar lavage (BAL) and transbronchial biopsy (TBB) did not differ. PH patients who underwent $\mathrm{BAL}$ and TBB had decreased $\mathrm{O}_{2}$ saturation during the procedure compared with the non-PH group $(23.5 \%$ vs $6.9 \%, P=0.033)$. No deaths were attributable to FB.

Conclusion: $\mathrm{PH}$ is common among COPD patients undergoing FB. PH patients undergoing $\mathrm{BAL}$ and TBB are at higher risk of decreased $\mathrm{O}_{2}$ saturation than those without $\mathrm{PH}$. Further studies should assess the risk among COPD patients with moderate-to-severe $\mathrm{PH}$.

Keywords: bronchoscopy, hypoxemia, pulmonary hypertension

\section{Introduction}

Flexible bronchoscopy (FB) is an invasive procedure performed by pulmonologists. ${ }^{1}$ The FB was performed under topical anesthesia and conscious sedation, and the procedure is considered safe, effective, and well tolerated in patients with a wide variety of pulmonary diseases. ${ }^{2}$ The estimated incidence of complications in bronchoscopy is $0.5 \%-4 \%{ }^{3}$ The most commonly recognized complications include hypoxia, bleeding, bronchospasm, cardiac dysrhythmias, and pneumothorax. ${ }^{4}$ Hypoxemia, mechanical ventilation, uremia, thrombocytopenia, use of anticoagulants, and pulmonary hypertension $(\mathrm{PH})^{5}$ are recognized risk factors of complications.

Studies have shown that patients with PH are at increased risk for adverse hemodynamic events after noncardiac surgery, ${ }^{6}$ with the highest risk among patients with severe $\mathrm{PH}^{7}$ In contrast, invasive procedures that require intravenous sedation have been reported as low risk. ${ }^{8}$

Bronchoscopy has been shown to affect hemodynamics, including a significant increase in pulmonary capillary wedge pressure. ${ }^{9}$ An acute pulmonary hypertensive 
response has been described in mechanically ventilated patients undergoing FB. ${ }^{10}$ It is unknown if these hemodynamic alterations result in clinically significant adverse events.

Therefore, patients with $\mathrm{PH}$ are generally considered to be at increased risk for complications from FB, particularly if a transbronchial biopsy (TBB) is performed. Among pulmonary physicians, $\mathrm{PH}$ are considered as risk factors for bleeding, although reports to support this concept are scant. ${ }^{11}$

Diaz-Guzman et al reported a retrospective analysis about performing $\mathrm{FB}$ in patients with $\mathrm{PH} .^{12}$ They found that FB could be performed safely in patients with mild and moderate $\mathrm{PH}$. However, the study was retrospective and included only a small number of patients. Furthermore, there is no consensus regarding the level of pulmonary artery pressure (PAP) considered to be safe for invasive diagnostic interventions such as TBB or transbronchial needle aspiration. In addition, in most cases the pulmonologists have no data concerning the $\mathrm{PH}$ degree of their patient. Therefore, we conducted this prospective study to assess the prevalence of $\mathrm{PH}$ in COPD population and the complication rate among patients undergoing FB.

\section{Patients and methods}

All COPD patients who underwent FB for the standard indications from October 2012 to September 2013 were screened for study eligibility. All fulfilled the Global initiative for chronic Obstructive Lung Disease criteria for diagnosis of COPD. The study was approved by the Institutional Review Board of Meir Medical Center, Israel (2010-0158). The National Institutes of Health number was NCT00986869. All patients included in the study provided written informed consent.

\section{Exclusion criteria}

Patients in whom PAP could not be assessed accurately by echocardiography were excluded from the study. All procedures were performed in the bronchoscopy suite of the Pulmonary Department at Meir Medical Center, Israel.

\section{Echo-Doppler study}

All patients underwent a Doppler echocardiogram on the day of the bronchoscopy, before the FB to evaluate PAP. PAP was calculated as the sum of the tricuspid regurgitation gradient and estimated right atrial pressure, provided there was no increase in pulmonic valve flow velocity. Echocardiograms were performed and transthoracic and peak values were reported for PAP. Maximal tricuspid regurgitation velocity (taken from all available views) was measured by continuous wave Doppler echocardiography to evaluate the pressure gradient from the right ventricle to the right atrium. Right atrial pressure was estimated on the basis of inferior vena cava size and inspiratory collapse. ${ }^{7,8} \mathrm{PH}$ was diagnosed based on PAP $>40 \mathrm{mmHg}$ estimated by Doppler echocardiography. PAP results were classified into three groups, mild $\mathrm{PH}$ for PAP 41-50 mmHg, moderate PH for PAP 51-60 mmHg, and severe PH for PAP above $61 \mathrm{mmHg}$.

\section{Bronchoscopy}

Fluoroscopy was available for all procedures. FB was performed by four trained pulmonary physicians who were blinded to the echocardiographic findings. Oxygen was administered to all the patients to ensure peripheral capillary oxygen saturation $\left(\mathrm{SpO}_{2}\right)>90 \%$ prior to introduction of the bronchoscope. Continuous pulse oximetry, electrocardiogram, and noninvasive blood pressure monitoring were obtained throughout the procedure. Sedation was achieved using midazolam and analgesic treatment included alfentanil 50-100 $\mu \mathrm{g}$. Topical anesthesia was obtained using 2\% lidocaine. All hemodynamic parameters including blood pressure, heart rate, and $\mathrm{O}_{2}$ saturation were monitored during and after the procedure, until the patient awoke and stabilized.

Bronchoscopy was performed with white light illumination in all patients and narrow band imaging in 47 patients (Olympus EVIS EXERA II, Olympus, Hamburg Germany). Interventions conducted during FB included bronchoalveolar lavage (BAL) for cytology and cultures in all cases, as well as endobronchial brushings, TBB, endobronchial biopsies, and transbronchial needle aspiration, as indicated.

\section{Data collection}

Data collected from all the patients included age, sex, medications, and baseline electrocardiogram results. Blood count and coagulation profile, as well as all details of bronchoscopic procedures, including indication for and duration of procedure were recorded.

\section{Outcome measures}

The primary outcome measure was the incidence of $\mathrm{PH}$ among patients who underwent FB. Secondary end points were complication rates including hypoxemia, hypotension, dysrhythmia, bleeding, and death in the study population.

Complications were defined for interventions including BAL only, and bronchoscopies including BAL and TBB. Complications were defined as hypoxemia $\left(\mathrm{SpO}_{2}<90 \%\right.$ and need for supplemental oxygen within 20 minutes of a completed procedure); hypotension (mean arterial pressure 
$<60 \mathrm{mmHg}$ or systolic blood pressure $<90 \mathrm{mmHg}$ for more than 5 minutes and/or need for administration of vasopressors). Additional possible complications were cardiac dysrhythmias, including new onset of arrhythmia or worsening of underlying arrhythmia that caused hemodynamic instability, and/or required urgent intervention, as well as bleeding or death.

The estimated amount of bleeding was defined as, none - minimal bleeding that did not require suctioning; mild bleeding - the need to continually suction the airways; moderate bleeding - the need for wedge FB in the segment involved; or severe bleeding - the need for additional interventions or transfusion.

\section{Statistical analysis}

Results were expressed as mean \pm SD for continuous variables. Qualitative data were expressed as percentage of patients. Nominal variables were compared using Pearson's chi-square or Fisher's exact test, each when appropriate. Continuous outcome variables were compared using Student's $t$-test. The risk factors found to be predictive of hypoxemia at univariate analysis were entered into a multivariate regression analysis to identify independent variables. Statistical significance was defined as $P<0.05$. Statistical analyses were performed using SPSS, version 18.0 (SPSS Inc., Chicago, IL USA).

\section{Results}

The study included 207 COPD patients; 167 (80.7\%) had normal pulmonary pressure and $40(19.3 \%)$ had PH. No patient was excluded due to known high PAP. The demographic and clinical characteristics of the study population are summarized in Table 1. Demographics were similar between the groups. There were more males than females in each group. The PH group was older than the group without $\mathrm{PH}, 69 \pm 15$ SD vs $59 \pm 16$ SD years, respectively $(P=0.001)$.

New York Heart Association classes in each group were similar; most patients were in classes II-III. As shown in Table 1, 40 patients (19.3\%) had $\mathrm{PH}$ based on echocardiogram criteria, 27 (13\%) had mild $\mathrm{PH}$, eight patients (3.9\%) had moderate $\mathrm{PH}$, and five patients $(2.4 \%)$ had severe $\mathrm{PH}$. All 13 patients with moderate or severe $\mathrm{PH}$ underwent repeated echocardiogram to reassess PAP. No significant changes were demonstrated.

Indications for FB and procedures performed are shown in Table 2. No statistical differences were observed between the groups. Pulmonary infiltrates and lung masses were the most common indications for FB.
Table I Characteristics of the study population $(n=207)$

\begin{tabular}{|c|c|c|}
\hline Parameters & $\begin{array}{l}\mathrm{PH} \\
(\mathrm{N}=40)\end{array}$ & $\begin{array}{l}\text { Non-PH } \\
(\mathrm{N}=167)\end{array}$ \\
\hline Age (years) ${ }^{\mathrm{a}}$ & $69 \pm 15$ & $59 \pm 16$ \\
\hline $\operatorname{Sex}(M: F)$ & $22: 18$ & $90: 77$ \\
\hline \multicolumn{3}{|l|}{ NYHA class } \\
\hline I & $24 \%$ & $30 \%$ \\
\hline II & $32 \%$ & $39 \%$ \\
\hline III & $30 \%$ & $20 \%$ \\
\hline IV & $14 \%$ & $11 \%$ \\
\hline \multicolumn{3}{|l|}{ Severity of $\mathrm{PH}(\mathrm{mmHg})$} \\
\hline Mild $(4 I-50)$ & $27(45 \pm 3.3)$ & \\
\hline Moderate $(5 I-60)$ & $8(56 \pm 2.3)$ & \\
\hline Severe $(>60)$ & $5(85 \pm 19)$ & \\
\hline
\end{tabular}

Notes: ${ }^{a} P=0.001$. Data are presented as mean $\pm S D$.

Abbreviations: NYHA, New York Heart Association; $\mathrm{PH}$, pulmonary hypertension; $M$, male; $F$, female.

Mean duration of FB was similar (20 \pm 4 SD minutes) in both groups. Mean midazolam dosages were higher in the non-PH group compared to the $\mathrm{PH}$ group $(3.0 \pm 1.2 \mathrm{SD} \mathrm{mg}$ vs 4.8 $\pm 3.5 \mathrm{SD} \mathrm{mg} ; P=0.009)$. The most common procedures performed were BAL in $139(83 \%)$ and $34(85 \%)$ and TBB in $104(62 \%)$ and $25(63 \%)$ patients in the non-PH and $\mathrm{PH}$ groups, respectively, without significant differences.

\section{Hemodynamic monitoring}

Vital signs as well as oxygen requirements before and after the procedure are described in Table 3. As noted, there were no significant differences in mean oxygen saturation, heart rate, or systolic blood pressure between the groups. Only diastolic blood pressure was slightly lower in the non-PH group.

Table 2 Indications for FB and additional procedures in COPD patients with and without $\mathrm{PH}$

\begin{tabular}{|c|c|c|}
\hline Parameter & $\begin{array}{l}\mathrm{PH} \\
(\mathrm{N}=40)\end{array}$ & $\begin{array}{l}\text { Non-PH } \\
(\mathrm{N}=167)\end{array}$ \\
\hline Indications & $\mathrm{N}(\%)$ & $\mathrm{N}(\%)$ \\
\hline Pulmonary infiltrates & $23(57.5)$ & $62(37)$ \\
\hline Hemoptysis & $3(7.5)$ & $18(11)$ \\
\hline Lung mass & $8(20)$ & $50(30)$ \\
\hline Suspected ILD (including sarcoidosis) & $2(5)$ & $22(13)$ \\
\hline Atelectasis & $2(5)$ & $2(1)$ \\
\hline Others & $2(5)$ & $13(8)$ \\
\hline Duration of FB (minutes) & $19 \pm 7$ & $21 \pm 8$ \\
\hline Midazolam (mg) ${ }^{\mathrm{a}}$ & $3.0 \pm 1.2$ & $4.8 \pm 3.5$ \\
\hline \multicolumn{3}{|l|}{ Procedures, N (\%) } \\
\hline BAL & $34(85)$ & $139(83)$ \\
\hline $\mathrm{BAL}+\mathrm{TBB}$ & $25(63)$ & $104(62)$ \\
\hline TBNA & I (2.5) & $13(7.7)$ \\
\hline
\end{tabular}

Notes: ${ }^{a}=0.009$. Data are presented as mean \pm SD.

Abbreviations: $\mathrm{PH}$, pulmonary hypertension; $\mathrm{BAL}$, bronchoalveolar lavage; FB, flexible bronchoscopy; ILD, interstitial lung disease; TBB, transbronchial biopsy; TBNA, transbronchial needle aspiration. 
Table 3 Hemodynamic parameters in COPD patients with and without $\mathrm{PH}$ who underwent flexible bronchoscopy $(\mathrm{n}=207)$

\begin{tabular}{llll}
\hline Parameter & $\begin{array}{l}\text { PH } \\
(\mathbf{N}=\mathbf{4 0})\end{array}$ & $\begin{array}{l}\text { Non-PH } \\
(\mathbf{N}=1 \mathbf{6 7})\end{array}$ & P-value \\
\hline $\mathrm{SO}_{2}$ before, \% & $95 \pm 3$ & $95.7 \pm 4$ & 0.082 \\
$\mathrm{SO}_{2}$ after, \% & $94.9 \pm 3$ & $95.8 \pm 6$ & 1.15 \\
$\mathrm{SO}_{2}$ lowest, \% & $93 \pm 5$ & $93 \pm 7$ & 0.994 \\
$\mathrm{HR}$ before (b/min) & $87 \pm 12$ & $86 \pm 14$ & 0.952 \\
$\mathrm{HR}$ after (b/min) & $93 \pm 19$ & $94 \pm 18$ & 0.454 \\
$\mathrm{DBP}$ before, $\mathrm{mmHg}$ & $80 \pm 10$ & $75 \pm 11$ & 0.015 \\
$\mathrm{DBP}$ after, $\mathrm{mmHg}$ & $83 \pm 13$ & $80 \pm 17$ & 0.427 \\
SBP before, $\mathrm{mmHg}$ & $133 \pm 25$ & $131 \pm 22$ & 0.636 \\
SBP after, $\mathrm{mmHg}$ & $132 \pm 22$ & $135 \pm 25$ & 0.476 \\
\hline
\end{tabular}

Note: Data are presented as mean \pm SD.

Abbreviations: DBP, diastolic blood pressure; HR, heart rate; $\mathrm{PH}$, pulmonary hypertension; SBP, systolic blood pressure; $\mathrm{SO}_{2}$, saturation of oxygen; b/min, beats per minute.

\section{Complication rates}

Complications are summarized in Table 4. Two patients (1.2\%) with normal pulmonary pressure developed supraventricular tachycardia. No patient developed hemodynamically significant dysrhythmias. Patients in the PH group who underwent BAL and $\mathrm{TBB}$ had a higher rate of hypoxemia compared to the non-PH group ( $23.5 \%$ vs $6.9 \%, P=0.033)$. As shown, among the patients who underwent BAL, only, the degree of hypoxemia was similar in patients with and without $\mathrm{PH}(P=0.420)$.

After entering age in logistic regression, we did not find a relationship between hypoxemia and $\mathrm{PH}$ (OR: 1.22, CI: 0.402-3.734). There was no statistically significant difference in bleeding scores or number of bleeding episodes between the groups. Bleeding rate was similar in all diagnostic interventions including BAL only and TBB (Table 4). Mean adrenalin dosage in $\mathrm{PH}$ and non- $\mathrm{PH}$ groups was similar (3.2 $\pm 1.7 \mathrm{SD}$ vs $3.4 \pm 2.2 \mathrm{SD} \mathrm{mg}, P=0.744)$. In addition, similar rates of wedge $\mathrm{FB}$ in the segment involved was noted

Table 4 Complications during bronchoscopy in COPD patients with and without $\mathrm{PH}$

\begin{tabular}{llll}
\hline Parameter & $\begin{array}{l}\text { PH } \\
\mathbf{( N = 4 0 )}\end{array}$ & $\begin{array}{l}\text { Non-PH } \\
(\mathbf{N}=\mathbf{I 6 7})\end{array}$ & P-value \\
\hline $\begin{array}{l}\text { Supraventricular tachycardia (N) } \\
\text { Hypoxemia }\end{array}$ & 0 & 2 & $\mathrm{I} .000$ \\
$\quad$ BAL, N (\%) & $3(8.8)$ & $\mathrm{I} 4(\mathrm{I0})$ & 0.420 \\
$\quad$ BAL + TBB, N (\%) & $9(23.5)$ & $\mathrm{I} 2(6.9)$ & 0.033 \\
Bleeding & & & \\
$\quad$ BAL, N (\%) & $7(\mathrm{I} 6.7)$ & $\mathrm{I} 7(\mathrm{I0})$ & 0.475 \\
$\quad$ BAL + TBB, N (\%) & $\mathrm{I} 2(29.4)$ & $57(34.5)$ & 0.686 \\
Adrenalin administered (mg) & $3.2 \pm \mathrm{I} .7$ & $3.4 \pm 2.2$ & 0.744 \\
Hypotension (N) & $\mathrm{I} / 40$ & $\mathrm{I} / \mathrm{I} 67$ & $0.34 \mathrm{I}$ \\
Death (N) & 0 & 0 & \\
\hline
\end{tabular}

Note: Data are presented as mean \pm SD.

Abbreviations: $\mathrm{PH}$, pulmonary hypertension; BAL, bronchoalveolar lavage; TBB, transbronchial biopsy. (two patients with $\mathrm{PH}$ and four patients without $\mathrm{PH}$, without significant differences), none required additional treatment to stop the bleeding.

There were no deaths attributable to the procedure. All patients who underwent FB in the bronchoscopy suite were discharged approximately 4 hours after it was completed and none required hospitalization or transfer to an intensive care unit.

\section{Discussion}

FB is considered a safe procedure among patients with mild $\mathrm{PH}$. To the best of our knowledge, this is the first prospective study to assess the incidence of $\mathrm{PH}$ and the complication rate among patients undergoing FB. We found that $\mathrm{PH}$ is relatively common in COPD patients undergoing FB (19.3\%), although most patients had a mild degree and only $6.3 \%$ presented with moderate or severe $\mathrm{PH}$. In this study, bronchoscopic procedures, including TBB, were not associated with an increased risk of bleeding in patients with mild $\mathrm{PH}$. The increased incidence of hypoxemia during TBB in COPD patients with $\mathrm{PH}$ is an important finding. However, episodes of hypoxemia were well tolerated and did not lead to clinically significant events.

Our findings are consistent with previous retrospective reports that assessed the safety of bronchoscopy in general and found it a safe procedure associated with a very low complication rate and negligible mortality. ${ }^{2}$ Several studies and survey analyses have estimated the rate of major complications regardless of the pulmonary pressure to be less than $2 \%$ when performed by experienced pulmonary physicians. ${ }^{12,13}$ Moreover, it has been demonstrated that FB can be performed safely in patients with COPD, asthma, and thrombocytopenia, as well as after myocardial infarction even though they are considered at risk for complications. ${ }^{14}$

Several features present in patients with $\mathrm{PH}$ are thought to increase the risk of complications with FB. Patients with severe $\mathrm{PH}$ often have right ventricular dysfunction and may be at risk for cardiac ischemia, arrhythmias, and hypotension. . $^{12,15}$ Additionally, chronic venous PH may cause dilation of the submucosal bronchial veins and their plexuses. ${ }^{18} \mathrm{FB}$ can also be associated with transient hypoxemia, ${ }^{19}$ which might be a particular concern in patients with $\mathrm{PH}$ who may be hypoxic at baseline and frequently have poor cardiorespiratory reserve. ${ }^{20}$ Finally, the presence of elevated pulmonary capillary pressure has been related to significant hemorrhage after TBB., 5,22

Significant bleeding after FB is infrequent. It has been suggested that $\mathrm{PH}$ is associated with an increased risk of hemorrhage and should be considered a contraindication for TBB.$^{23}$ Evidence to support the concept that elevated pressure 
at the capillary level might increase the risk of bleeding in patients with $\mathrm{PH}$ is limited. Despite the lack of available studies, a survey reported that up to $40 \%$ of pulmonary physicians considered PAPs of $\geq 40 \mathrm{mmHg}$ a contraindication for transbronchial lung biopsy (TBB). ${ }^{24}$ In our study, we found that PAP between 41 and $50 \mathrm{mmHg}$ is common (13\%). However, no significant risk existed in this population.

Schulman et $\mathrm{a}^{25}$ prospectively studied the occurrence of bleeding in heart transplant recipients who underwent TBB for the evaluation of parenchymal lung disease. The incidence of moderate hemorrhage $(25-100 \mathrm{~mL})$ was $15 \%$ when mean PAP was above $16 \mathrm{mmHg}$. Other reports have found lower rates of hemorrhage. In an animal model of induced $\mathrm{PH}$, an increase in PAP (12-33 mmHg) did not increase the risk of bleeding. ${ }^{26}$ Morris et al investigated the risk for hemorrhage in 21 patients with interstitial lung disease and echocardiographic evidence of $\mathrm{PH}$ who underwent $\mathrm{TBB}$ and found evidence of bleeding in only one patient. ${ }^{27}$ In our cohort, a significant portion of the patients developed bleeding requiring adrenalin (Table 4). However, all cases were treated without need for additional modalities except wedging.

Our patients with $\mathrm{PH}$ were significantly older than those with normal pulmonary pressure. Heart disease presenting as diastolic dysfunction can partially explain this finding. However, despite that, these older patients did not develop more complications.

FB can also be associated with cardiovascular complications such as hypotension, arrhythmias, and cardiac arrest. ${ }^{17,28,29}$ A study of FB performed under topical anesthesia found significant increases in mean arterial pressure and heart rate and an $86 \%$ increase in pulmonary capillary wedge pressure. These hemodynamic changes were similar during passage through the larynx and during suctioning. ${ }^{9}$

Hemodynamic complications after FB appear to be rare. A recent study that included more than 20,000 procedures, reported an incidence of cardiac arrhythmias of $1 \%$, including three deaths from cardiopulmonary arrest $(0.013 \%) .{ }^{13}$ Invasive hemodynamic monitoring was not performed in our study. However, there were only two episodes of supraventricular tachycardia, both in patients with normal PH; no significant clinical or electrocardiographic evidence of cardiac ischemia were noted. Similarly, no patient developed respiratory failure or death associated with the procedure.

This study has several limitations. First, PAP was measured by echocardiography and not by right heart catheterization, the gold standard for assessing pulmonary pressure. However, echocardiography is a well validated measure to assess pulmonary pressure. ${ }^{7,8}$ Moreover, in clinical practice, the decision to forego $\mathrm{FB}$ is based on echocardiogram and not on pulmonary catheterization results. Second, the definition of bleeding was subjective. However, we staged the bleeding according to its severity and recorded the amount of adrenalin used. Third, the FB was performed by four pulmonologists and this could be a source of bias because of different techniques. Finally, we had only 13 patients with moderate-to-severe $\mathrm{PH}$ who underwent FB. Therefore, our results should be interpreted cautiously in this subgroup.

\section{Conclusion}

Our study found that the incidence of PH among COPD patients undergoing FB is $19.3 \%$ and that FB can be performed safely in COPD patients with mild PH. COPD patients with $\mathrm{PH}$ undergoing $\mathrm{BAL}$ and $\mathrm{TBB}$ are at higher risk for decreased oxygen saturation during the procedure compared to those without PH. Large prospective studies with hemodynamic measurements are needed to confirm these findings in patients with moderate-to-severe PH.

\section{Acknowledgments}

This study was not supported by external funding. The authors would like to thank Faye Schreiber, MS, for editorial assistance and Nava Yelin, MSc, for statistical analysis.

\section{Author contributions}

YN made contributions to study design, acquisition and interpretation of data. MK drafted, revised, and submitted the final manuscript. AM designed the study, drafted and revised the submitted article. AB-S contributed to acquisition of data. AG contributed to acquisition and interpretation of data. DS contributed to study design, acquisition of data, analysis and interpretation of data; drafted and revised the submitted article; provided final approval of the version to be published; and is guarantor of the study. All authors contributed toward data analysis, drafting and critically revising the paper and agree to be accountable for all aspects of the work.

\section{Disclosure}

The authors report no conflicts of interest in this work.

\section{References}

1. Colt HG, Prakash UBS, Offord KP. Bronchoscopy in North America: survey by the American Association for Bronchology, 1999. J Bronchol. 2000;7:8-25.

2. Ernst A, Silvestri GA, Johnstone D. Interventional pulmonary procedures: guidelines from the American College of Chest Physicians. Chest. 2003;123:1693-1717

3. Pue CA, Pacht ER. Complications of fiberoptic bronchoscopy at a university hospital. Chest. 1995;107:430-432. 
4. Pereira W Jr, Kovnat DM, Snider GL. A prospective cooperative study of complications following flexible fiberoptic bronchoscopy. Chest. 1978:3:813-816.

5. American Thoracic Society. Medical section of the American Lung Association. Guidelines for fiberoptic bronchoscopy in adults. Am Rev Respir Dis. 1987;136:1066.

6. Ramakrishna G, Sprung J, Ravi BS, Chandrasekaran K, McGoon MD. Impact of pulmonary hypertension on the outcomes of noncardiac surgery: predictors of perioperative morbidity and mortality. $\mathrm{J} \mathrm{Am} \mathrm{Col}$ Cardiol. 2005;45:1691-1699.

7. Currie PJ, Seward JB, Chan KL, et al. Continuous wave Doppler determination of right ventricular pressure: a simultaneous Doppler catheterization study in 127 patients. J Am Col Cardiol. 1985;6:750-756.

8. Kircher BJ, Himelman RB, Schiller NB. Noninvasive estimation of right atrial pressure from the inspiratory collapse of the inferior vena cava. Am J Cardiol. 1990;66:493-496.

9. Lundgren R, Haggmark S, Reiz S. Hemodynamic effects of flexible fiberoptic bronchoscopy performed under topical anesthesia. Chest. 1982;82:295-299.

10. Bein T, Pfeifer M, Keyl C, et al. Right ventricular function and plasma atrial natriuretic peptide levels during fiberbronchoscopic alveolar lavage in critically ill, mechanically ventilated patients. Chest. 1995;108:1030-1035.

11. Wahidi MM, Rocha AT, Hollingsworth JW, Govert JA, FellerKopman D, Ernst A. Contraindications and safety of transbronchial lung biopsy via flexible bronchoscopy. A survey of pulmonologists and review of the literature. Respiration. 2005;72:285-295.

12. Diaz-Guzman ED, Vadi S, Minai OA, Gildea TR, Mehta AC. Safety of diagnostic bronchoscopy in patients with pulmonary hypertension. Respiration. 2009;77:292-297.

13. Gorman SR, Beamis JF. Complications of flexible bronchoscopy. Clin Pulm Med. 2005;12:177-183.

14. Jin F, Mu D, Chu D, Fu E, Xie Y, Liu T. Severe complications of bronchoscopy. Respiration. 2008;76:429-433.

15. Dweik RA, Mehta AC, Meeker DP, Arroliga AC. Analysis of the safety of bronchoscopy after recent acute myocardial infarction. Chest. 1996;110:825-828.
16. Rich S, McLaughlin VV, O'Neill W. Stenting to reverse left ventricular ischemia due to left main coronary artery compression in primary pulmonary hypertension. Chest. 2001;120:1412-1415.

17. Runo JR, Loyd JE. Primary pulmonary hypertension. Lancet. 2003;361:1533-1544.

18. Credle WF Jr, Smiddy JF, Elliott RC. Complications of fiberoptic bronchoscopy. Am Rev Respir Dis. 1974;109:67-72.

19. Ohmichi M, Tagaki S, Nomura N, Tsunematsu K, Suzuki A. Endobronchial changes in chronic pulmonary venous hypertension. Chest. 1988;94:1127-1132.

20. Milman N, Faurschou P, Grode G, Jørgensen A. Pulse oximetry during fibreoptic bronchoscopy in local anaesthesia: frequency of hypoxaemia and effect of oxygen supplementation. Respiration. 1994;61:342-347.

21. Barst RJ. Medical therapy of pulmonary hypertension. An overview of treatment and goals. Clin Chest Med. 2001;22:505-509.

22. AARC clinical practice guideline. Bronchoscopy assisting -2007 revision and update. Respir Care. 2007;52:74-80.

23. Du Rand IA, Barber PV, Goldring J. British Thoracic Society guidelines on diagnostic flexible bronchoscopy. Thorax. 2011;56(suppl 1): i1-i21.

24. Zavala DC. Pulmonary hemorrhage in fiberoptic transbronchial biopsy. Chest. 1976;70:584-588.

25. Schulman LL, Smith CR, Drusin R, Rose EA, Enson Y, Reemtsma K. Utility of airway endoscopy in the diagnosis of respiratory complications of cardiac transplantation. Chest. 1988;93:960-967.

26. Morris MJ, Peacock MD, Lloyd WC, Blanton HM. The effect of pulmonary hypertension upon bleeding in sheep undergoing bronchoscopic biopsy. J Bronchol. 1996;3:11-16.

27. Morris MJ, Peacock MD, Mego DM, Johnson JE, Anders GT. The risk for hemorrhage from bronchoscopic lung biopsy due to pulmonary hypertension in interstitial lung disease. J Bronchol. 1998;5:117-121.

28. Herf SM, Suratt PM, Arora NS. Deaths and complications associated with transbronchial lung biopsy. Am Rev Respir Dis. 1977;115:708-711.

29. Suratt PM, Smiddy JF, Gruber B. Deaths and complications associated with fiberoptic bronchoscopy. Chest. 1976;69:747-751.
International Journal of COPD

\section{Publish your work in this journal}

The International Journal of COPD is an international, peer-reviewed journal of therapeutics and pharmacology focusing on concise rapid reporting of clinical studies and reviews in COPD. Special focus is given to the pathophysiological processes underlying the disease, intervention programs, patient focused education, and self management protocols.

\section{Dovepress}

This journal is indexed on PubMed Central, MedLine and CAS. The manuscript management system is completely online and includes a very quick and fair peer-review system, which is all easy to use. Visit http://www.dovepress.com/testimonials.php to read real quotes from published authors. 